\title{
Straighthead and Agronomy Characters Testing for Selected Parent Lines and Hybrid Combinations at UAPB in 2011-2012
}

\author{
Bihu Huang ${ }^{*}$, Zongbu Yan ${ }^{2}$ \\ ${ }^{1}$ University of Arkansas at Pine Bluff, Pine Bluff, AR, USA \\ ${ }^{2}$ Texas A\&M AgriLife Research Center, Beaumont, TX, USA \\ Email: "huangb@uapb.edu \\ Received 11 May 2016; accepted 19 July 2016; published 22 July 2016 \\ Copyright (C) 2016 by authors and Scientific Research Publishing Inc. \\ This work is licensed under the Creative Commons Attribution International License (CC BY). \\ http://creativecommons.org/licenses/by/4.0/ \\ Open Access
}

\begin{abstract}
Straighthead disease is a physiological disorder in rice and the most widespread non-fungal disease of the U.S. straighthead greatly reduces rice yield. Straighthead studies were most conducted in the artificial field which was Arsenic amendment plots due to the similarity of straighthead symptoms of Arsenic damage. To evaluate the straighthead disease resistance in natural condition, 46 rice lines, including 24 inbred lines and 22 hybrid combinations which were developed from breading program, were chosen for straighthead and agronomy characters testing in a native soil where straighthead naturally induced in the past years at University of Arkansas at Pine Bluff (UAPB), Arkansas in 2011 and 2012. The straighthead of rice were rated from 0 to 9 levels, and 0 was the least straighthead disorder and 9 was the most severe straighthead disorder. Cocodrie (CCDR) was used as the check in this study. The results of 2011 showed that the yields of 8 entries were higher than the check CCDR. The straighthead scores of these 8 entries were 0 - 1 which indicated their resistance to straighthead. The rest of the entries had lower yields than check CCDR with straighthead scores 5 - 6 which indicated their moderate susceptibility to straighthead. The yields were negatively related to the straighthead scores $(r=-0.9178, P<0.01)$. The results of 2012 showed that the yields of 9 hybrids and 6 inbred entries were higher than the check CCDR. The straighthead scores of top 12 entries were 0 - 2 which indicated that they were resistant to straighthead and 3 entries with straighthead score of 3 which indicated they were moderately resistant to straighthead. The rest 3 hybrids and 4 inbred entries had lower yields than the check and their straighthead scores were 5 - 6 which indicated their moderately susceptible to straighthead. The yields was negatively related to the straighthead scores $(r=-0.956, P<0.01)$. Compared to CCDR, the yield of hybrids showed their straighthead resistance at some extent. The yields of top six entries, hybrid 33A/PB23, inbred 3053, hybrid 28s/PB22, 28s/PB24, 29s/PB24 and inbred 3222 , were 10,376.4, 9991.4, 9566.7, $9334.3,9183.9$ and $9174.3 \mathrm{Kg} / \mathrm{Ha}$, and $46.0 \%, 40.7 \%, 34.7 \%$,
\end{abstract}

\footnotetext{
${ }^{*}$ Corresponding author.
} 
$31.4 \%, 29.3 \%$, and $29.5 \%$ higher than the check, respectively.

Keywords

Straighthead, Hybrids, Natural Field of Straighthead Occurrence

\section{Introduction}

Straighthead disease is a physiological disorder in rice that results in sterile florets with distorted lemma and palea. The panicles or heads may not form at all in extreme cases (Figure 1). Straighthead disorder is the most widespread non-fungal oldest rice disease in Arkansas, and has been observed since the early 1900s when rice was first grown in Arkansas [1]. Yield losses can approach 100\% when a highly susceptible variety is planted on a soil with a history of severe straighthead and is not drained and dried prior to panicle initiation [2] [3]. For example, yield losses of $94 \%$ were observed in Cocodrie [4], a long grain cultivar that has played a major role in southern rice production since 2000 [5]. Yield reduction due to straighthead has been reported in the United States, Argentina, Australia, Brazil, Columbia, Japan, Portugal, Thailand and Vietnam [6]. The symptoms of arsenic (As) injury to rice are similar to straighthead, therefore incorporation of As in the form of monosodium methanearsonate (MSMA) has become the common practice for evaluating rice susceptibility to straighthead [4] [7]-[10]. Evaluation using MSMA is the only method available and is still utilized for assessment of straighthead susceptibility of new cultivars in the Uniform Rice Regional Nursery (URRN) jointly in Arkansas, Louisiana, Mississippi, Missouri and Texas. However, MSMA will be banned from using in crops by the US Environmental Protection Agency because it is a hazardous contaminant to ground water. Thus a naturally site of straighthead evaluation will benefit southern US rice breeders in the future. The field in the farm of University of Arkansas at Pine Bluff (UAPB) had been found straighthead since 2008 when we started to do rice breeding. The objectives of this study were to evaluate the straighthead, test the agronomy characters and select the straighthead resistant varieties in the field where straighthead naturally induced.

\section{Methods and Materials}

This experiment was conducted at UAPB (University of Arkansas at Pine bluff, USA) farm (Latitude: $34^{\circ} 15^{\prime} \mathrm{N}$, Longitude: $92^{\circ} 01^{\prime} \mathrm{W}$, Elevation: 70.7 meters) in 2011 and 2012. Forty-six rice lines, including 32 (CCDR and Francis used for both years) inbred lines and 12 hybrid combinations were randomized block designed with 4 Replications. Each Entry was with 1 row $\times 1 \mathrm{~m} \times 0.4 \mathrm{~m}$, Sowing 15 seeds per row but keeping 10 plants per row. Cocodrie is known to be susceptible (S) to straighthead, so it has been widely used as a susceptible check in studies of straighthead; $150 \mathrm{~kg} / \mathrm{h}^{2}$ of urea and $300 \mathrm{~kg} / \mathrm{h}^{2}$ of N.P.K. (13-13-13) were applied 2 times, respectively. Insecticide was applied 3 times and no any fungicide was applied. Straighthead severity was recorded at physiological maturity by using a 0 - 9 rating scale: "0" rating indicating no signs of stress with $>90 \%$ seed set and no parrot beaking or twisting of panicles, and "9" rating for plants that are stunted and do not extrude panicles described by Yan et al. [2]:

0: $91 \%-100 \%$ of grains developed and no apparent damage at all;

1: $81 \%$ - $90 \%$ of grains developed and no apparent damage;

2: $71 \%-80 \%$ of grains developed and $96 \%-100 \%$ of panicles completely emerged;

3: $61 \%-70 \%$ of grains developed and $91 \%$ - $95 \%$ of panicles completely emerged;

4: $41 \%$ - $60 \%$ of grains developed and $86 \%$ - $90 \%$ of panicles completely emerged;

5: $21 \%-40 \%$ of grains developed and $81 \%-85 \%$ of panicles completely emerged, initial appearance of distorted and parrot-break grains;

6: $11 \%$ - $20 \%$ of grains developed and $76 \%$ - $80 \%$ of panicles completely emerged;

7: $0 \%$ - 10\% grains developed and most panicles completely emerged but totally upright;

8: no grains developed and $0 \%-10 \%$ of panicles emerged; and

9: no panicles emerged with stubby plants.

The samples for agronomy characters testing were harvested after straighthead scoring and the rest of data were collected at harvest for each plot of entry at the time of ripening. Data analyzed by using SAS 12.0 for the 

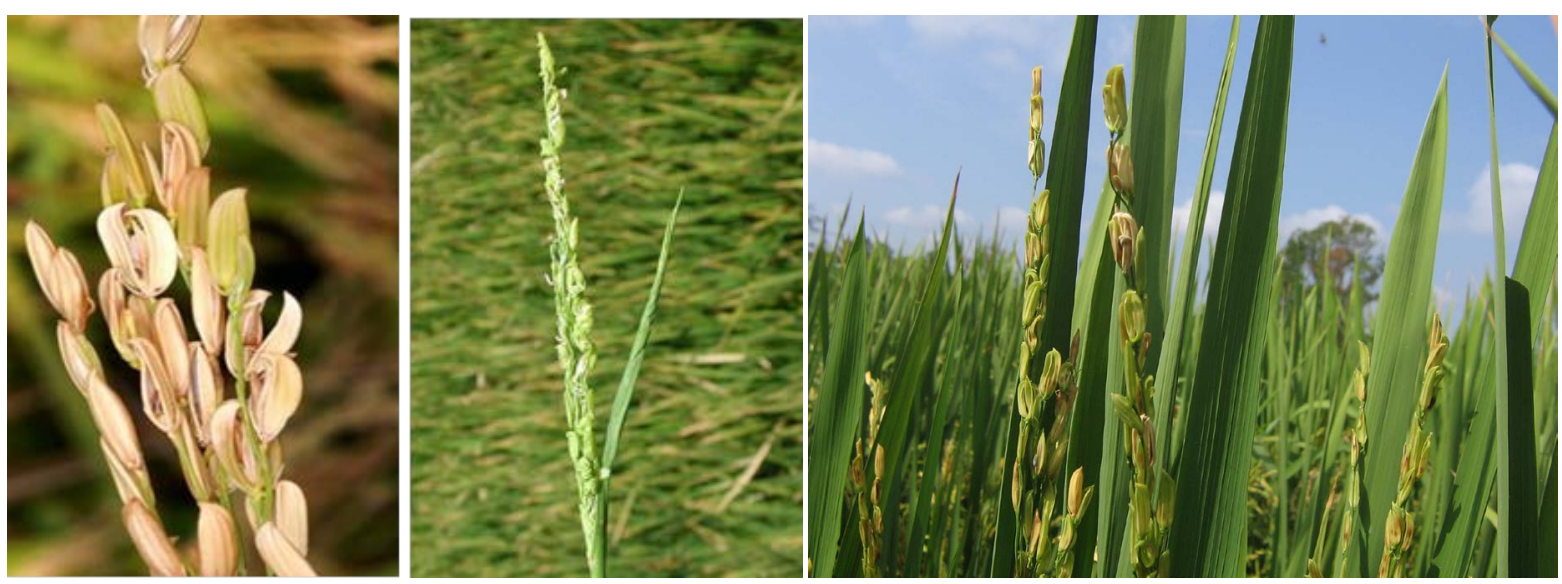

Figure 1. Straighthead disorder after maturity (left) and before maturity (middle and right).

standard error and correlation.

\section{Results and Discussions}

In year 2011, a total of 24 lines were tested and the results presented in Table 1. Cocodrie (CCDR) has been wide used in Arkansas rice production and is known to be susceptible (S) to straighthead. As the check, the straighthead score of CCDR was 5 which indicated moderate susceptible to straighthead this year. Eight varieties, 9-718, 9-710, Rondo, PB-12, 9-186, PB-13, PB-2, and PB-11, had straighthead score 1 or 0 which indicated very resistant to straighthead. The rest entries' strsaighthead scores were 5 or 6 which indicated the moderate susceptibility to straighthead. The yield of CCDR was $5073.5 \mathrm{Kg} / \mathrm{Ha}$. The yields of the 8 entries were higher than the check CCDR. The yields of the top 3 lines, 9-718, 9-710, and Rondo were 8698.4, 8098.6, and 8071.85 $\mathrm{Kg} / \mathrm{Ha}$, and over check by $71.5 \%, 59.6 \%$, and $59.1 \%$, respectively. The yields of other 5 lines, PB-12, 9-186, PB-13, PB-2, and PB-11 were 6562.1, 6471.8, 6126.8, 6034.0, and 5587.7 Kg/Ha, and over check 29.3\%, 27.6\%, $20.8 \%, 18.9 \%$, and $10.1 \%$, respectively. The yields of the rest of entries were below the check and their straighthead scores were 5 or 6 which indicated the moderate susceptibility to straighthead. Those entries included Francis and Jasmine-85which were widely used in Arkansas rice production. Their low yields in this field were due to their higher straighthead disorder (Table 1). The yields of the entries tested in 2011 were highly lated $(\mathrm{r}=-0.910, \mathrm{P}<0.01)$ to straighthead scores. The yields significantly decreased when the straighthead creased (Figure 2).

In year 2012, 12 hybrids and 12 inbred lines were tested and the results presented in Table 2. The straighthead score for the check CCDR was 5 which indicated the moderate susceptibility to straighthead. There were 15 entries, 9 hybrids and 6 inbred lines, had lower straighthead scores (0-3) and higher yields than the check. The yields of top 8 entries, 33A/PB23, 3035, 28s/PB22, 28s/PB24, 29s/PB24, 3222, 28s/PB23, and 2854 were 10,376.4, 9991.4, 9566.7, 9334.3, 9183.9, 9174.3, 8659.5, and 8542.6 Kg/Ha and over check 46.0, 40.6, 34.6, 31.4, 29.3, 29.1, 21.9, and 20.2\%, respectively. The yields of other 7 entries from ID number 8 to 16 were also showed 19.3\% 2.2\% higher than check CCDR which yield was $7105.2 \mathrm{Kg} / \mathrm{Ha}$. The yields of the rest of 8 entries were lower than CCDR and their straighthead scores were rated 5or6 which indicated their moderate susceptibility to straighthead. The yields of the entries planted in 2012 were highly correlated $(\mathrm{r}=-0.956, \mathrm{P}<0.01)$ to straighthead scores. The yields significantly decreased when the straighthead increased (Figure 3). Most of the hybrid lines showed higher resistance to straighthead and had higher grain yields and panicles per plant than conventional cultivars (Table 2).

\section{Conclusion}

Straighthead reduced the yield for susceptible varieties. Most of the hybrid lines showed higher resistance to straighthead and had higher grain yields than conventional cultivars. Twelve inbred varieties, 9-718, 9-710, Rondo, PB-12, 9-186, PB-13, PB-2, PB-11, 3035, 3222, 2854, and 3137, showed highly resist to straighthead, and can be used in hybrid breeding. Four hybrids 33A/PB23, 28s/PB22, 28s/PB24, and 29s/PB24 can be further 
Table 1. Yields, seed set rates and straighthead of inbred lines in 2011.

\begin{tabular}{|c|c|c|c|c|c|c|c|}
\hline Order & Name of line & Yield & STD Error & Over check & Seed set & Grain weight & Straighthead score \\
\hline & & $\mathrm{Kg} / \mathrm{Ha}$ & & (\%) & (\%) & g/1000 seeds & \\
\hline 1 & CCDR(check) & 5073.5 & 1376.2 & 0 & 76.4 & 19.6 & 5 \\
\hline 2 & $9-718$ & 8698.4 & 686.6 & 71.5 & 71.3 & 28.3 & 0 \\
\hline 3 & $9-710$ & 8098.6 & 692.6 & 59.6 & 77.4 & 26.8 & 0 \\
\hline 4 & Rondo & 8071.7 & 675.0 & 59.1 & 80.2 & 22.1 & 0 \\
\hline 5 & PB-12 & 6562.1 & 736.8 & 29.3 & 72.3 & 27.2 & 0 \\
\hline 6 & $9-186$ & 6471.8 & 653.0 & 27.6 & 72.1 & 23.3 & 0 \\
\hline 7 & PB-13 & 6126.8 & 709.0 & 20.8 & 75.2 & 23.8 & 1 \\
\hline 8 & PB-2 & 6034.0 & 80.0 & 18.9 & 61.9 & 24.3 & 1 \\
\hline 9 & PB-11 & 5587.7 & 348.7 & 10.1 & 75.9 & 27.8 & 0 \\
\hline 10 & PB-9 & 4657.7 & 588.9 & -8.2 & 71.8 & 20.8 & 5 \\
\hline 11 & PB-6 & 4616.0 & 219.7 & -9.0 & 70.6 & 20.2 & 5 \\
\hline 12 & $9-185$ & 4577.9 & 1048.0 & -9.8 & 65.8 & 21.3 & 5 \\
\hline 13 & $9-721$ & 4567.8 & 330.3 & -10.0 & 66.6 & 24.4 & 5 \\
\hline 14 & PB-18 & 4141.6 & 915.3 & $-18,4$ & 51.7 & 26.6 & 5 \\
\hline 15 & $9-712$ & 4075.6 & 1090.4 & -19.7 & 65.7 & 28 & 5 \\
\hline 16 & Francis & 3923.0 & 468.1 & -22.7 & 72.8 & 17.9 & 5 \\
\hline 17 & PB-5 & 3881.1 & 215.1 & -23.5 & 58.6 & 22.9 & 5 \\
\hline 18 & Jansmine-85 & 3817.5 & 622.4 & -24.8 & 38 & 19.9 & 5 \\
\hline 19 & PB-1 & 3748.6 & 683.2 & -26.1 & 70.8 & 20.7 & 5 \\
\hline 20 & $9-184$ & 3412.7 & 898.3 & -32.7 & 38.3 & 23.4 & 6 \\
\hline 21 & $9-725$ & 3272.2 & 92.9 & -35.5 & 53.4 & 26.4 & 6 \\
\hline 22 & $9-720$ & 2987.0 & 921.6 & -41.1 & 71.1 & 24.5 & 6 \\
\hline 23 & $9-714$ & 2747.0 & 140.4 & -45.9 & 57 & 25.1 & 6 \\
\hline 24 & $9-726$ & 2574.0 & 161.1 & -49.3 & 62.6 & 28.6 & 6 \\
\hline
\end{tabular}

Data of 2011



Figure 2. The relationship between yield and straighthead for the data of 2011. 
Table 2. Straighthead and agronomy characters of Hybrids 2012.

\begin{tabular}{|c|c|c|c|c|c|c|c|c|}
\hline ID & Inbred or hybrid & Yield & STD Error & Over check & Height & Panicle & Seed set & $\begin{array}{l}\text { Straighthead } \\
\text { score }\end{array}$ \\
\hline & & $\mathrm{Kg} / \mathrm{Ha}$ & & $\%$ & $\mathrm{~cm}$ & No/Plant & $\%$ & \\
\hline 1 & CCDR (check) & 7105.2 & 599.9 & 0 & 99.9 & 9.9 & 86.9 & 5 \\
\hline 2 & 33A/PB23 & 10376.4 & 1049.4 & 46.0 & 115.7 & 14.4 & 82.8 & 0 \\
\hline 3 & 3035 (8-2/Rondo) & 9991.4 & 458.6 & 40.6 & 101.3 & 12.6 & 83.6 & 0 \\
\hline 4 & 28s/PB22 & 9566.7 & 80.3 & 34.6 & 118.9 & 15.9 & 84 & 0 \\
\hline 5 & 28s/PB24 & 9334.3 & 123.5 & 31.4 & 117.4 & 14.1 & 84.9 & 0 \\
\hline 6 & 29s/PB24 & 9183.9 & 321.5 & 29.3 & 116.7 & 14.3 & 85.7 & 0 \\
\hline 7 & 3222 (Rondo/8-7) & 9174.3 & 1186.8 & 29.1 & 101.8 & 14.3 & 78.4 & 0 \\
\hline 8 & 28s/PB23 & 8659.5 & 1177.6 & 21.9 & 120.6 & 16.8 & 86 & 1 \\
\hline 9 & 2854 (8-12/Jasime-85) & 8542.6 & 837.0 & 20.2 & 102.7 & 15.3 & 84.9 & 1 \\
\hline 10 & 30s/PB23 & 8494.4 & 262.5 & 19.6 & 115.9 & 13.8 & 85.6 & 1 \\
\hline 11 & 3137 (Rondo/8-7) & 8421.2 & 826.3 & 18.5 & 98.3 & 15.4 & 84.7 & 2 \\
\hline 12 & 2527 (8-16/Rondo) & 8256.5 & 948.1 & 16.2 & 99.7 & 14.2 & 88.8 & 1 \\
\hline 13 & 33A/PB5 & 8098.0 & 1527.5 & 14.0 & 121.6 & 15.8 & 80.2 & 1 \\
\hline 14 & 3168 (Rondo/8-7) & 7554.1 & 1193.0 & 6.3 & 96.8 & 12.8 & 78.2 & 3 \\
\hline 15 & 28s/PB5 & 7143.0 & 1347.2 & 0.5 & 115.9 & 14.1 & 67.5 & 3 \\
\hline 16 & 33A/PB5 & 6948.1 & 789.2 & -2.2 & 115.6 & 13 & 78.8 & 3 \\
\hline 17 & Francis & 6931.9 & 474.2 & -2.4 & 102.6 & 8.7 & 87.2 & 5 \\
\hline 18 & 33A/PB21 & 6859.2 & 1385.0 & -3.5 & 117.7 & 14.4 & 68.9 & 3 \\
\hline 19 & 28s/PB21 & 6034.2 & 629.3 & -15.1 & 105.6 & 12 & 66.4 & 5 \\
\hline 20 & 30s/PB21 & 6022.6 & 808.3 & -15.2 & 111 & 14.2 & 74.8 & 5 \\
\hline 21 & 3468 (Francis/8-18) & 5608.2 & 399.3 & -17.1 & 98.6 & 7 & 88.9 & 6 \\
\hline 22 & 3054 (Francis/8-13) & 5575.0 & 360.2 & -21.5 & 98.1 & 7.8 & 83.3 & 6 \\
\hline 23 & 3084 (Francis/8-13) & 5197.4 & 728.0 & -26.9 & 103.1 & 11.3 & 88.9 & 6 \\
\hline 24 & 3957 (Francis/8-13) & 5052.3 & 212.8 & -28.9 & 87.7 & 12 & 77.1 & 6 \\
\hline
\end{tabular}

Data of 2012

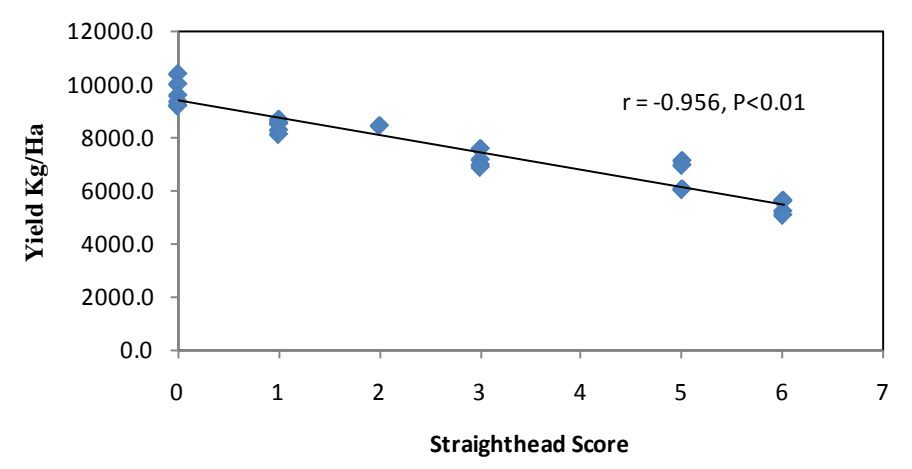

Figure 3. The relationship between yield and straighthead for the data of 2012. 
tested for the use in the rice production in future.

\section{References}

[1] Scott, B. and Cartwright, R. (2002) Glyphosate Injury or Straighthead? Delta Farm Press. http://deltafarmpress.com/mag/farming_glyphosate_injury_straighthead/

[2] Yan, W., Dilday, R.H., Tai, T.H., Gibbons, J.W., McNew, R.W. and Rutger, J.N. (2005) Differential Response of Rice Germplasm to Straighthead Induced by Arsenic. Crop Science, 45, 1223-1228. http://dx.doi.org/10.2135/cropsci2004.0348

[3] Wilson Jr., C.E., Cartwright, R., Lorenz, G. and Stiles, S. (2010) My Rice Field Is No Yielding Well, What Happened? In: Arkansas Rice on Sep. 8, UA CES. http://arkansasrice.blogspot.com/2010 0901 archive.html

[4] Wilson Jr., C.E., Slaton, N.A., Frizzell, D.L., Boothe, D.L., Ntamatungiro, S. and Norman, R.J. (2001) Tolerance of New Rice Cultivars to Straighthead. In: Norman, R.J. and Beyrouty, C.A., Eds., B.R. Wells Rice Research Studies 2000. AR Agri. Exp. Sta. Res. Ser. 485, University of Arkansas, Fayetteville, 428-436.

[5] Linscombe, S.D., Jodari, F., Bollich, P.K., Groth, D.E., White, L.M., Chu, Q.R., Dunand, R.T. and Sanders, D.E. (2000) Registration of “Cocodrie” Rice. Crop Science, 40, 292-294. http://dx.doi.org/10.2135/cropsci2000.0007rcv

[6] Yan, W., Agrama, H.A., Slaton, N.A. and Gibbons, J.W. (2008) Soil and Plant Mineral Associated Rice Straighthead Disorder Induced by Arsenic. Agronomy Journal, 100, 1655-1661. http://dx.doi.org/10.2134/agronj2008.0108

[7] Horton, D.K., Frans, R.E. and Cothren, T. (1983) MSMA-induced Straighthead in Rice (Oryza sativa) and Effect upon Metabolism and Yield. Weed Science, 31, 648-657.

[8] Frans, R., Horton, D. and Burdette, L. (1988) Influence of MSMA on Straighthead, Arsenic Uptake and Growth Response in Rice. University of Arkansas, Agri. Exp. Sta., Fayetteville, Res Ser 302, 1-12.

[9] Dunn, B.W., Batten, G.D., Dunn, T.S., Subasinghe, R. and Williams, R.L. (2006) Nitrogen Fertilizer Alleviates the Disorder Straighthead in Australian Rice. Australian Journal of Experimental Agriculture, 46, 1007-1083. http://dx.doi.org/10.1071/EA05004

[10] Slaton, N.A., Wilson Jr., C.E., Ntamatungiro, S., Notman, R.J. and Boothe, D.L. (2000) Evaluation of New Varieties to Straighthead Susceptibility. In: Norman, R.J. and Beyrouty, C.A., Eds., B.R. Wells Rice Research Studies 1999, AR Agri. Exp. Sta. Res. Ser. 476, University of Arkansas, Fayetteville, 313-317.

\section{Submit or recommend next manuscript to SCIRP and we will provide best service for you:}

Accepting pre-submission inquiries through Email, Facebook, LinkedIn, Twitter, etc.

A wide selection of journals (inclusive of 9 subjects, more than 200 journals)

Providing 24-hour high-quality service

User-friendly online submission system

Fair and swift peer-review system

Efficient typesetting and proofreading procedure

Display of the result of downloads and visits, as well as the number of cited articles

Maximum dissemination of your research work

Submit your manuscript at: http://papersubmission.scirp.org/ 